\title{
Epilepsy Surgery in Children
}

\author{
Vera Cristina Terra, Américo C Sakamoto and Hélio Rubens Machado \\ Centro de Cirurgia de Epilepsia (CIREP), Departamento de Neurociências e Ciências do \\ Comportamento. Faculdade de Medicina de Ribeirão Preto - USP. Ribeirão Preto - SP, \\ Brazil
}

\section{Introduction}

Epilepsy is a neurological condition that accompanies mankind probably since its inception. About 400 years before Christ, the disease was already known by Hippocrates, who wrote the book "On The Sacred Disease", in which it refuted the idea that the upheaval was the work of spirits and wisely related to brain. This concept was not fully accepted until modern era (Horsey, 1886). Classically, epilepsy is defined as a chronic disease with recurrent seizures, that affects individuals in all age groups, and affects $1-2 \%$ of children (Rasmussen, 1983). In childhood, epilepsy is more common in the first year of life, and its incidence decreases progressively with increasing age, affecting approximately 100 children per 100,000 births in the first year of life, 40 children for every 100,000 births in subsequent years, and approximately 20 individuals per 100,000 adolescents (Obeid et al, 2009a). In 75\% of these cases, seizures are well controlled with antiepileptic drugs and in the remaining $25 \%$, epilepsy is refractory to pharmacological treatment and surgical approach should be considered (Terra-Bustamante et al, 2005).

The definition of intractability is not easy and many factors such as age of epilepsy onset, classical evolution of the specific epileptic syndrome, seizure frequency and epilepsy etiology should be considered. The goal of epilepsy surgery is complete resection of the epileptogenic zone, thus allowing patients to a greater chance of cure or disease control, with a better behavioral, cognitive and intellectual development, especially when considering the pediatric group. In these lines, early indication for surgery may allow children have better development and social inclusion (Lippé et al, 2010). It is estimated that $90 \%$ of brain growth and maturation occur until five years of age and intense dendritic synaptic connections remained until the age of seven, making this a favorable period for better post-operative recovery. In children the occurrence of neuronal plasticity is maximal and several eloquent cortical areas have great ability to reorganize its circuits, and can be functionally represented in both cerebral hemispheres (Obeid et al, 2009a; Benifla et al, 2009). It is known that the early indication for surgery is the single most important factor in getting good results, and that anti-epileptic drugs do not alter the long-term prognosis of epilepsy drug resistance, therefore, surgical treatment should not be postponed.

When considering epilepsy surgery, some concepts should be established to achieve better seizure control (Obeid et al, 2009b):

- Epileptogenic zone: cortical area responsible for seizure generation, whose removal is sufficient to leave patient seizure free. 
- Symptomatogenic zone: cortical area responsible for the symptoms of epileptic seizures, almost always contained or near the epileptogenic zone, but whose removal is not necessary for seizure control.

- Irritative zone: cortical area involved in generating interictal epileptiform discharges.

- Ictal onset zone: area where seizures began detected by the electroencephalogram.

- Epileptogenic lesion: lesion or anatomical area macroscopically visible on imaging studies, which may be responsible for seizures generation, which usually is included in the epileptogenic zone, but may be smaller than it.

Considering these definitions, the gold standard of epilepsy surgery is complete resection of the epileptogenic zone, thus allowing patients to become seizure free. Today are considered preferable candidates for epilepsy surgery patients that have defined refractory epilepsies, with no involvement of eloquent areas and with a well-defined epileptogenic zone. However this is not always possible, especially when considering the pediatric group (Lippé et al, 2010). The first challenge is when define pharmacological refractoriness. Some authors suggest that patient should have been submitted for at least three different drugs, for at least two years, appropriated to the type of seizure and / or epileptic syndrome, at doses related to weight and age, excluding possible idiophatic syndromes of childhood with transitory refractoriness. This controversial definition may have catastrophic meaning when considering small children with more severe forms of epilepsy, where surgery in the first year of life may be essential for neurological and cognitive development (Dunkley et al, 2011). In the same way should be considered the risk of developing post-operative sequelae. In some patients it is acceptable the occurrence of motor deficits considering the severity of the disease.

It is worthwhile to emphasize the differences between epilepsy in children and in adults (Villarejo \& Comair, 2000). Although there are many similarities, and much of the knowledge of epilepsy in children is extrapolated from studies in adults, there are relevant differences, which influence pre-operative decisions and surgical techniques. Also, children have a lower threshold to seizures, which results in an increased occurrence of catastrophic epilepsies (and consequent development delay). Regarding the pathological substrate, the epilepsies related to extensive brain lesions are relatively common in the pediatric age group, as opposed to mesial temporal sclerosis, whose incidence is several times higher in adults. Moreover, the seizure semiology and electrophysiological data in pediatric epilepsies are distinct of that observed in adults, with more generalizes symptoms and diffuse electrographic patterns in children even in focal epilepsies (Tsiptsios et al, 2010; Hnojciková et al, 2010).

Unlike epilepsy in adults, childhood mesial temporal sclerosis has a lower incidence, occurring in $39 \%$ of children versus $87 \%$ in adults (Obeid et al, 2009a). Among the etiological factors, cortical development malformation is overwhelmingly the most frequent, followed by brain tumors, gliosis and finally the mesial temporal sclerosis. Other common etiologies for epilepsies in children are tuberous sclerosis, Sturge-Weber syndrome and Rasmussen encephalitis

Defined the diagnosis of refractory epilepsy, patient need to be referred to an epilepsy surgery center. The pre-surgical evaluation usually include a detailed medical history, a high resolution brain magnetic resonance image (MRI), ictal and interictal videoelectroencephalogram (VEEG), neuropsychiatric assessment, psychiatric evaluation and social interview. In this way is preferable that patient is evaluated by a multidisciplinary team. In selected cases, brain computed tomography, single photon emission tomography (SPECT) or positron emission tomography (PET) may be indicated. The analysis of all these 
tests will determine the next step to be followed: epilepsy surgery, exams complementation or refuse surgery. Other exams that may also be indicated are functional MRI (mainly for motor and language localization), quantitative MRI and intra-operative electrocorticography (ECoG).

Brain MRI is the test of choice in defining the presence or not of a potential epileptogenic lesion and concordance with video-electroencephalogram findings is crucial for a better prognosis. However, in many children a multifocal interictal pattern or multiple seizure types may be present. In this way it is essential that video-electroencephalogram is analyzed by an experienced neurophysiologist that is able to recognize age related specific syndromes and determined if they have a focal or generalized onset. With the advance of image techniques, syndromes previous considered as generalized are now identified in some cases as localized (Chugani, 1994). The main example is children with West Syndrome with typical spasms and electrographic hypsarrhythmia pattern that may be secondary to focal lesions or focal functional abnormal brain areas. In some of these children, relatively small resections may be sufficient to seizure control (Asano et al, 2001) and surgery should not be refused.

\section{Childhood epilepsy syndromes}

\subsection{West syndrome}

West syndrome is a severe epileptic syndrome occurring in 1 in 2000-4000 live births. The syndrome has a triad consisting of development regression with mental retardation, epileptic spasms and EEG hypsarrhythmia. It may be found in previously normal children (probable symptomatic forms) or occur in children with development delay observed before seizure onset, with identifiable brain lesions (symptomatic forms) (Sakakihara, 2011).

Epileptic spasms are brief movements involving both up and lower limbs, usually with arm flexion and lower limbs extension. Other forms of spasms that may be observed are extension of up and lower limbs and asymmetric or lateralized spasms. Ocular movements as circular or lateral nystagmus are frequently observed in seizures. Seizures usually begin in the first year of life and have a poor prognosis progressing with increasing age for more complex epilepsy and other syndromes (mainly the Lennox-Gastaut syndrome or unspecific symptomatic generalized epilepsies).

The electroencephalogram typically shows hypsarrhythmia (chaotic pattern with disruption and attenuation of the background rhythm, combined with slowing and multifocal epileptiform discharges) (Sakakihara, 2011).

Response to pharmacological treatment is generally poor and the classical association of valproic acid and a benzodiazepine is still recommended. Vigabatrin has been considered a better choice especially for patients with tuberous sclerosis complex (Pesaturo et al, 2011). Alternative therapies as the use of steroids or ketogenic diet may contribute do seizure control in some patients. Surgical treatment may be indicated in some cases, particularly in patients with focal brain lesions or functional localized abnormalities detected by PET scan (Obeid et al, 2009a).

\subsection{Lennox-Gastaut}

One of the most severe epileptic syndrome characterized by atypical absence, axial tonic/atonic seizures, slow spike-wave complex and bursts of fast rhythms at 10 to $20 \mathrm{~Hz}$ during sleep on EEG. Mental retardation, behavioral disturbances and others seizure types 
are usually present, mainly complex partial, generalized tonic-clonic and myoclonic seizures. Children with this syndrome may develop several seizures per day, with the installation of atypical absence status epilepticus. This condition may occur in previously normal children or in patients with signs of brain damage and has major impact on cognitive development. On the other hand, tonic, atonic and myoclonic seizures are frequently associated with repetitive trauma requiring the use of helmets to prevent head injuries. Typical electroencephalographic interictal pattern may be associated with multifocal spikes or sharp waves, with marked background disorganization.

Treatment is primarily pharmacologic and polytherapy is usually indicated. Recently, the use of rufinamida has been associated with great improvement in seizure frequency, but it is not common to have patients that becoming seizure free (Wier et al, 2011). In the same way as West Syndrome, some patients may have benefit of localized cortical resection, but callosotomy or vagus nerve stimulation is frequently the only options (García-March et al, 2008; Benifla et al, 2006) with some authors reporting satisfactory response.

\subsection{Landau-Kleffner}

Landau-Kleffner syndrome is a rare condition characterized by aphasia, auditory agnosia and epileptic seizures (Obeid et al, 2009a). The main symptom is the regression of language through persistent aphasia in a previously normal child that may develop mutism or autistic regression. Seizures occur in $70-80 \%$ of patients, but may be rare, with good response to antiepileptic drugs.

The EEG in wake state may be normal, but with somnolence typically shows bitemporal independent epileptiform discharges, that are activated by sleep involving the rolandic areas. MRI is normal and treatment with corticosteroids, ACTH or immunoglobulin appears to slow the evolution of language deficit (Snead III \& Martien, 2001). Surgery with multiple subpial transections may be proposed (Cross et al, 2006) but there are few studies showing some improvement in respect of language evolution. Vagus nerve stimulation may also be tempted to reduce cognitive impairment (Park, 2003).

\subsection{Focal epilepsies of childhood}

Focal epilepsies in children may be associated with a large number of pathologies, such as abnormalities of cortical development, hypoxic-ischemic lesions, benign tumors, phakomatosis and mesial temporal sclerosis. Extratemporal neocortical epilepsies predominate in most of the described series. As in adults, symptoms of seizures will be related to the lobe involved but age of epilepsy onset may modify this paradigm. In this way, patients with mesial temporal epilepsies secondary to cortical development malformation may present in the firsts years of life with tonic seizures or even with a typical West Syndrome. When epilepsy settles latter, especially if children is older than three to six years, complex partial seizures predominate with simple automatisms. Typical automatisms with dystonic posturing will be present latter on, usually after six years (Mohamed et al, 2001). Extratemporal epilepsies may manifest as in adults with more exuberant symptoms, but auras are less frequently reported although some children may be capable of describe simple visual aura or sensitive symptoms.

Seizure frequency may be high even in temporal lobe epilepsies, with daily seizures. Long term prognosis is variable and in symptomatic cases, a significant proportion of children evolve with refractory forms of epilepsy that may persist true adulthood. In this way, the 
option of a surgery should be considered early to avoid cognitive and social impairment secondary to chronic seizures (Mohamed et al, 2001).

Surgery proposed will depend on the etiology and localization of the lesion and one of the most striking factors is the complete lesion resection. Differently from adult epilepsies, here the goal should be permit a better cognitive and motor development, especially when considering the most catastrophic forms of epilepsies. In temporal lobe epilepsies, long term follow up is similar to that observed in adults, with almost 70 to $80 \%$ of patients being seizure free.

\subsection{Status epilepticus}

Refractory status epilepticus occurs when seizures are not controlled with initial benzodiazepine therapy or a subsequent anticonvulsant drug therapy used in a methodological way (Abend \& Dlugos, 2008). When seizures persist other options, such as surgery, must be considered (Whelless, 2010). Surgical approaches include focal cortical resections, hemispherectomies, multiple subpial transections, and rarely corpus callosotomy and vagus nerve stimulator implantation. Focal resective surgery is usually indicated in patients with localized brain lesions and electrographic evidence of ictal focal seizure onset (Vendrame \& Loddenkemper, 2010). Defining the optimal moment to indicate surgery and which patients may benefit from a cortical resection or a palliative procedure is not easy. There are few series of patients evaluated until now and timing and criteria for intervention need to be stated.

\subsection{Cortical development malformation}

Cortical development malformation are congenital diseases that are associated with intractable epilepsy in both children and adults, being the most frequent pathology found in pediatric epilepsy in surgery centers (Cepeda et al, 2006). The advances in MR images have increased the number of patients diagnosed with this pathologies and consequently undergoing surgical treatment (Chern et al, 2010). Younger cases are more likely to have multilobar and severe forms of cortical development malfromations compared with older patients with focal and mild lesions (Figure 1).

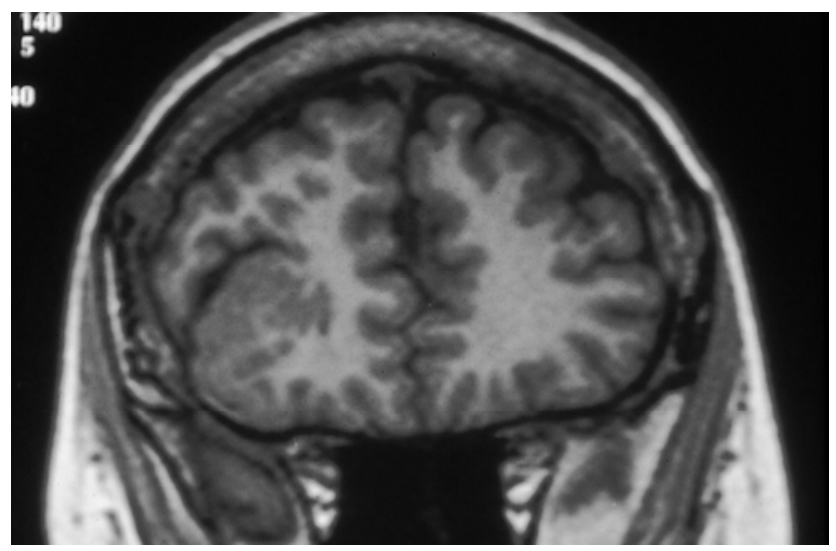

Fig. 1. Magnetic resonance image of a frontal polymicrogyria. 
Seizures symptoms are usually related to lesion localization an age of epilepsy onset and MRI is the exam of choice to confirm diagnosis. The best option to treat refractory cases is the complete resection of the lesion and the associated epileptogenic zone (Diaz et al, 2008).

\subsection{Tuberous sclerosis}

Tuberous sclerosis is a multisystem genetic disease, autosomal dominant, with variable phenotypic expression, with an incidence of $1 / 58.000$ (Connolly et al, 2006). Approximately $80-90 \%$ of individuals with tuberous sclerosis will develop epilepsy throughout his life. The syndrome results to two known mutations: one on the gene TSC1 located on chromosome 9 (9q34 region) that encodes the protein hamartin; and the other on the TSC2 gene, localized on chromosome 16 (region 16p13.3) that encodes the expression of tuberin (Connolly et al, 2006). Its features include the presence of pathognomonic cerebral cortical tubers, subependymal nodules, retinal lesions, disseminated sebaceous adenomas (Figure 2), subcutaneous fibrous plaques (especially on the scalp) and renal angiomyolipomas (Connolly et al, 2006). Subependymal giant cell astrocytoma (SEGA) may be present and evolve with obstruction of the ventricular system and hydrocephalus. In some patients, this tumor may have a more malignant evolution and surgery is the treatment of choice.

The EEG is normal in only $12 \%$ of cases of tuberous sclerosis. In the remaining cases, localized or multifocal frequent epileptiform discharges are present. West syndrome may be the clinical presentation form, mainly when seizures start in the first year of life.

Treatment should be directed to seizure types and Vigabatrin may be the first option when epileptic spasms are present. Surgery of choice is tuberectomia, and although the great majority of the patients have numerous tubers, in some selected cases it is possible to identify just on tuber as being epileptogenic, with approximately $60 \%$ of the patients submitted to tuberectomy being seizure free (Moavero et al, 2010). There is considerable controversy whether the remaining lesions may become epileptogenic or not. The use of intracranial EEG recording with chronically implanted electrodes may contribute to seizure localization. When ressective surgery is not possible, palliative procedures may be proposed as callosotomy or vagus nervous stimulator.

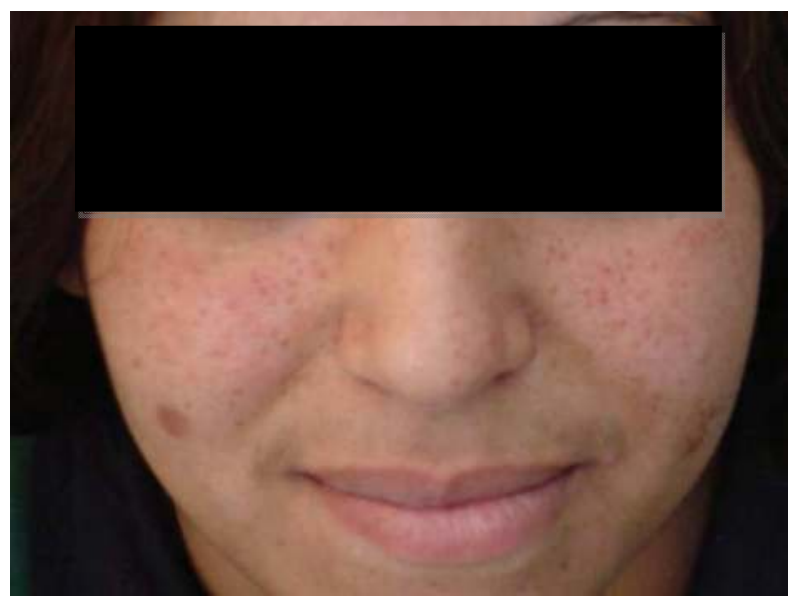

Fig. 2. Patient with the diagnosis of tuberous sclerosis with facial sebaceous adenomas. 


\subsection{Sturge-Weber syndrome}

Sturge-Weber syndrome or encephalon angiomatosis is a rare neurocutaneous disorder characterized by a leptomeningeal angiomatosis. Main clinical features include the presence of facial port wine nevus recognized at birth usually in the distribution of branches of the trigeminal nerve. Symptoms classically started in childhood but persist true adulthood. Intractable epilepsy will be present in $75-90 \%$ of patients, $60 \%$ of them candidates for surgical treatment. Congenital glaucoma, progressive hemiparesis, learning disabilities and leptomeningeal angiomatosis are usually present (Di Rocco \& Tamburrini, 2006).

The diagnosis is confirmed by brain MRI that characteristically demonstrates brain volume loss in T1 sequences, with loss of superficial vascularization and leptomeningeal enhancement after gadolinium administration. T2 sequences shows confirm these findings and may demonstrate the presence of coarse calcifications, although computed tomography scans may be the exam of choice to identify calcified lesions. Hemispheric angiomatosis predominates but some patients have a more localized lesion, with involvement of posterior regions being more frequent. The electroencephalogram usually shows nonspecific or diffuse hemispheric changes.
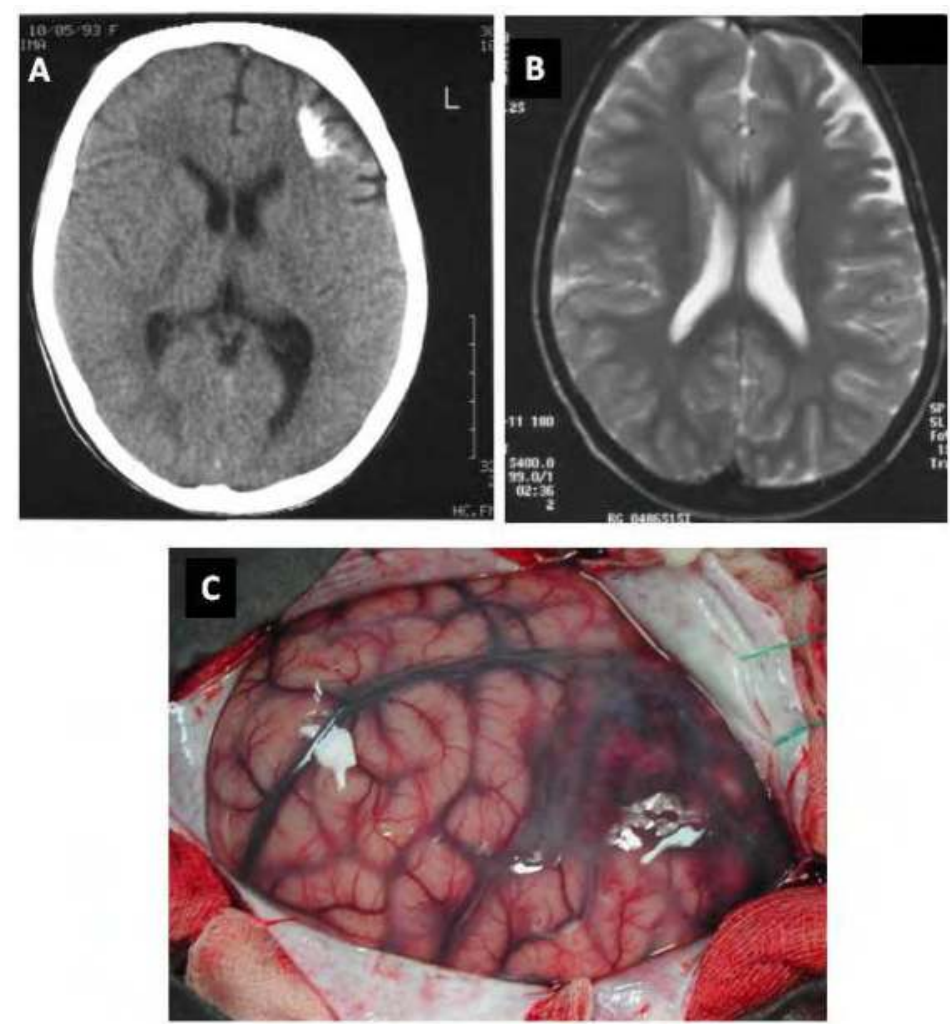

Fig. 3. Frontal lobe lesion of Sturge-Weber syndrome. A. Computerized tomography showing a coarse calcification. B. MRI with frontal focal atrophy. C: Intra-operative classical leptomeningeal angiomatosis. 
Surgery may be an option in patients with refractory epilepsies and complete excision of the angiomatous cortex is the most appropriate treatment. The installation of permanent neurological deficits needs to be discussed.

\subsection{Rasmussen encephalitis}

First described by Theodore Rasmussen in 1958, this rare disease probably has an immunemediated substrate, related to both humoral and T lymphocytes, usually affecting one brain hemisphere, and leading to progressive atrophy with loss of neurological function (Mastrangelo et al, 2010; Bien et al, 2005). The age of onset is between three and seven years of life, but there are descriptions of cases that seizures initiate in adulthood. Progressive hemiparesis, mental retardation and behavioral changes can settle in evolution. Seizures is classically hemi-clonic and syndrome may have a fast devastating evolution, with the installation of motor deficits and continuous motor seizures in few months or have a more slowly evolution. Language disorders are common when disease involve the dominant hemisphere, even if seizures started in early ages.

EEG shows delta waves include polymorphic in the affected hemisphere associated with asynchronous slow waves and epileptiform discharges. MRI demonstrates in initial phases an enhancement of signal in T2 or FLAIR sequences in insula or motor strip. With disease evolution unilateral enlargement of the ventricles and other cerebrospinal fluid spaces, basal ganglia and cortical atrophy, mainly in central regions develop and may be identified in T1 or T2 sequences.

Therapy with corticosteroids or immunosuppressors can be used, but the treatment of choice that provides better results is the hemispheric surgery (Hart et al, 1998; Villemure \& Mascott, 1995; Villemure \& Daniel, 2006).

\subsection{Brain tumors}

Brain tumors are common cause of refractory epilepsy in children. The most frequently tumor types observed are gangliogliomas, dysembryoplastic neuroepithelial tumors, pilocytic astrocytomas, oligodendrogliomas and ependymomas. The hypothalamic hamartomas constitute a very especial tumor type, with characteristic symptoms. The treatment of choice is surgery, that can provide substantial benefit reducing seizure frequency and severity and allows the identification of tumor type (Tian et al, 2011).

The hypothalamic hamartoma is a congenital lesion of the tuber cinereum presenting with the classic triad of gelastic seizures (generally characterized by tearfulness or laughter), central precocious puberty and behavioral disturbance. Its clinical course is often progressive, with mental development deteriorating and the occurrence of major complex partial or tonic seizures. Recent studies have demonstrated the intrinsic epileptogenicity of hamartoma (Maixner, 2006).

EEG may be normal or show unspecific diffuse slowing. MRI is characteristic, showing a rounded lesion, with regular edges, hypointense on T1 and T2, firmly adhered to the mammillary bodies and the thalamus (Maixner, 2006). The treatment of precocious puberty is essentially clinical. Surgery is recommended as the sole indication for improvement of epilepsy, with resection or disconnection of the lesion (Machado et al, 1991; Siwanuwatn et al, 2008; Yasargil \& Abdulrauf, 2008).

\subsection{Non-lesional epilepsies}

Recently, an increasing number of studies had been reported considering epilepsy surgery for the treatment of refractory epilepsy in non-lesional epilepsies. Long term follow up 
demonstrate that patients with normal MRI submitted to surgery have a overall smaller chance of being seizure free after surgery, independent of the lobe of the resection (TéllezZenteno et al, 2010). A similar outcome had been reported in children and adults

\section{Surgical techniques}

Following the establishment of drug refractory epilepsy and completion of comprehensive preoperative evaluation, surgical treatment can be offered, according to the results of this assessment, being driven primarily by underlying disease and the region to be addressed. Patients may be submitted to resective or palliative procedures, depending on pre-operative exam conclusions with surgical techniques following the general standards established in pediatric neurosurgical practice.

The operating room should be wide to allow the presence a multidisciplinary team consisted of anesthesiologist, neurosurgeons and neurophysiologists. Surgeries in children are usually extensive. Craniotomies and subsequent durotomy should be broad, allowing intraoperative electrographic study and exposure of the anatomical landmarks of each procedure. Most commonly used incisions are:

- $\quad$ "Question-mark"or "inverted question mark, " initiated at the root of the zygoma and extended superiorly to the superior temporal line or above, more frequent used for temporal lobe or hemispheric surgeries.

- "Barn Door" or "barn door", which facilitates approaches involving multiple lobes, starting frontally on the previous line of insertion of the hair and then passing the following paramedian lambdoid suture.

- Bicoronal or classical, mainly for frontal lobe approach.

Intraoperative electrocorticography is currently used to localize seizure onset, guiding extension of resection. This has a particular importance in patients with brain tumors, cortical development malformations and other neocortical lesions. Although evidence that support its utility is controversial, many pediatric centers use it routinely (Gallentine \& Mikati, 2009). Cortical stimulation during surgery in children is usually restricted to motor area strip localization. It's a reliable and safe technique and its use in children may need an experienced electrophysiologist, since higher amperage thresholds is frequently necessary.

Intraoperative ultrasound, neuronavigation and surgical microscopes are fundamental tools currently used in epilepsy surgery. In particular, neuronavigation represent a potential technique that permit a better identification of lesions limits contributing to complete resection (Stone \& Rutka, 2008).

\subsection{Resective procedures}

Resective surgeries are the procedure of choice in patients with refractory epilepsies and involve part of a lobe, an entire lobe or multiple lobes, depending on the extension of the epileptogenic zone.

\subsubsection{Lesionectomies}

Advances in neuroimaging allowed the identification of discrete anatomical lesions that are correlated with seizure onset. In some patients, the resection of such a lesion is sufficient to achieve seizure freedom, being an efficient modality for medically intractable epilepsies 
(Bourgeois et al, 2006). Focal resections may be indicated in the cases that electrographic ictal findings are strictly localized and coincident with lesions such as small tumors, cortical development malformations, cavernous angiomas, etc. (Figure 4). The extent of the resection will be determined by the nature of the lesion and intraoperative electrocorticography findings, especially in patients with cortical development malformation. Patients with persistency of seizures may need extension of the initial resection with a lobectomy.
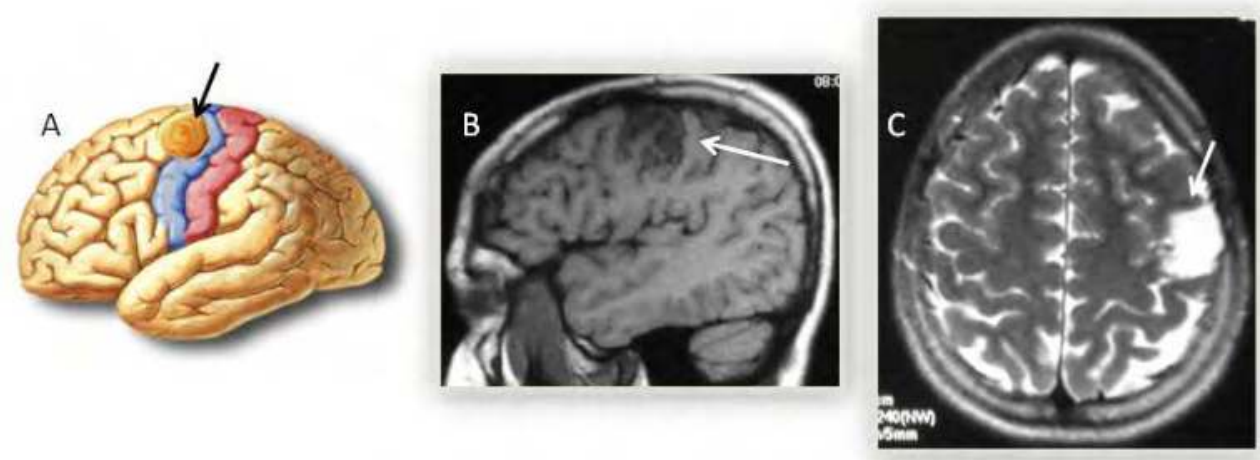

Fig. 4. Peri-rolandic epilepsy - surgical technique. A: schematic image ilustrating the localization of the brain lesion (arrow). B: sagital and C: Axial post-operative magnetic resonance image showing resection region.

\subsubsection{Lobectomies}

Lobectomies consist of the resection of an entire or almost entire lobe. It may be done in any lobe, but in most cases involve the temporal lobe. Frontal and parietal resections are limited to motor strip that may be identified during surgery by direct cortical stimulation and the use of neuronavigation. Occipital resections are limited by the parieto-occipital sulcus.

Extratemporal resections constitute the largest percentage of surgical procedures for epilepsy in children, and refer to isolated lobectomies (partial or full frontal - paramedially frontopolar and lateral convexity, parietal, occipital), or delimited corticectomias and multilobar resections. The most common pathology in these cases is cortical dysplasia, followed by tumors. Cortical resection in the rolandic region in children with intractable epilepsy is possible, but usually results in worsening or the development of new sensory or motor deficits. Accurate mapping of regions of functional cortex and epileptogenic zones may minimize these deficits with a satisfactory seizure outcome (Benifla et al, 2009). Some authors consider the possibility of direct cortical stimulation with awake craniotomy in children, but a careful neuropsychometric and neuropsychiatric evaluation should be carried out pre-operatively (Tobias \& Jimenez, 1997). Overall outcome of extratemporal resections is usually inferior to that observed in temporal lobectomies (Harkness, 2001).

In children, temporal lobe epilepsy associated with mesial temporal sclerosis corresponds approximately for $40 \%$ of surgeries above six year old. Patients with temporal lobe epilepsy are usually divided into three groups (Adelson, 2001) to better define the therapeutic strategy: A first group refers to cases of typical mesial temporal sclerosis, which indicates 
the standard resection, these patients have good prognosis after surgery (seizure control in $70 \%$ of cases (Villarejo et al, 2000). A second group includes the temporal tumors, in which we chose to perform temporal lobectomy with amygdalo-hippocampectomy. The tumor resection is the most important factor that influences the postoperative prognosis (Iannelli et al, 2000). The last group concerns the temporal cortical dysplasia, most often neocortical and should be guided by resection electrographic findings and, if possible, remove extensive cortical abnormalities that may be present. Standard temporal lobectomy involves resection of 4 to $4.5 \mathrm{~cm}$ (nondominant hemisphere) or 3.5 to $4 \mathrm{~cm}$ (dominant hemisphere) from the tip of the temporal lobe, resection of the amygdala and hippocampus after entry into the temporal horn of lateral ventricle.

\subsubsection{Hemispheric surgeries}

Hemispherotomy and its variations are generally performed in hemiparetic patients with severe, intractable epilepsy arising from one cerebral hemisphere. The neurosurgeon Walter E. Dandy already described hemispheric surgeries technique in the early twentieth century (Dandy, 1928), with performance of anatomical resection. Since a high long term complications rate was observed with this procedure, surgery approach was modified with the development of combined limited brain resection and disconnection. In 1983, Rasmussen described his elegant technique for hemispheric disconnection associated with small resections. Since then many techniques have been developed, such as hemidecortication, and techniques of disconnection by parasagittal (Delalande \& Dormuller, 2008), trans-sylvian (Binder \& Schramm, 2006) and peri-insular (Villemure \& Mascott, 1995). The surgical technique to be chosen will depend on the conformation of the pathological brain, and also the familiarity and experience of the surgical team.

Hemispherotomy (Figure 5) is the surgical procedure of choice for cases of Rasmussen encephalitis, hemimegalencephaly, atrophy and porencephaly hemispheric ischemic sequelae of arterial trunks, among other diseases and in some series seizure freedom is nearly 70 to $80 \%$ (Limbrick et al, 2009). Motor and cognitive outcomes after hemispherectomy are variable and depend on many predictors including etiology and duration of seizure disorder, age at the time of surgery, premorbid status, and postsurgical seizure control and an effective rehabilitative program is essential after surgery (Samargia \& Kimberley, 2009).

\subsection{Palliative procedures}

In patients were it is not possible to demarcate precisely the epileptogenic zone, but with incapacitating epilepsies, palliative procedures may be proposed. The goals of these procedures are based in the fact that a favorable impact with respect to quality of life may be achieved with the reduction of the morbidity and the number of seizures. This result may permit reduction of the amount of anti-epileptic drugs, with a better behavioral, cognitive and intellectual development. In general, palliative procedures are indicated in patients with high seizure frequency, patients with drop attacks with repetitive trauma or patients with more severe forms of epilepsy syndrome. Medically intractable tonic and atonic seizures may be responsive to either vagus nerve stimulation or corpus callosum section, with less morbidity with the first and greater likelihood of seizure improvement with the second (Rosenfeld \& Roberts, 2009). 

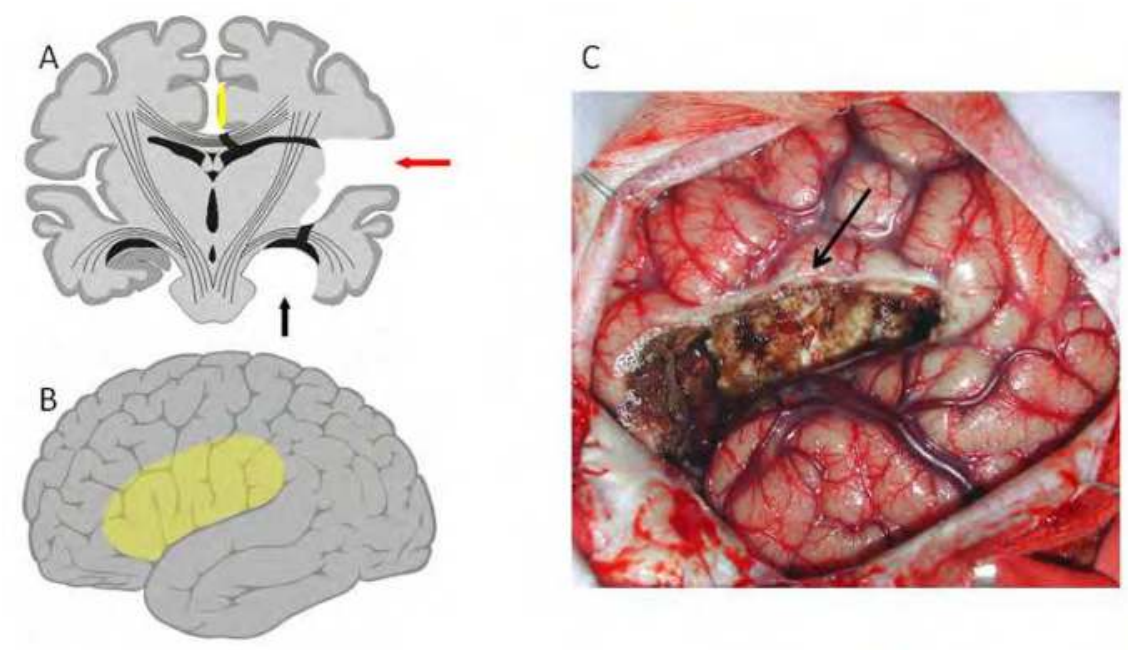

Fig. 5. Hemispherotomy consist of a resection of the insular lobe and the mesial portion of the temporal lobe, with disconnection of the temporal peduncle, basal ganglia and callosotomy (A and B). C: Intra-operative image demonstrating the insular resection.

\subsubsection{Vagus nerve stimulation}

Vagus nerve primary function is parasympathetic regulation of autonomic visceral activity and influences many regions of central nervous system, through its extensive connectivity. Inputs first achieve the nucleus of solitary tract and then projects to reticular formation, hypothalamus, hippocampus, amygdale, dorsal raphe nucleus, locus ceruleus, thalamus and cerebral cortex. This widespread cortical influence was first described in 1938 by Bailey \& Bremer, however, the exact mechanisms by which vagus nerve stimulation reduce seizure frequency is still unknown.

The system consists of a generator positioned in the chest wall, near the clavicle and an electrode that is implanted around the vagus nerve in the neck. The generator is programmed externally with increasing current according to seizure frequency. Optimal stimulation parameters, interval between each programming and the high limits of stimulation have yet to be determined (McLachlan, 2001).

The efficacy and safety of vagus nerve stimulation has been studied in several patients, including adults and children with refractory epilepsies, with satisfactory results even in small children (Alexopoulos et al, 2006; Benifla et al, 2006; García-March et al, 2008; Elliot et al, 2009; Coykendall et al, 2010; Elliot et al, 2011). It may be indicated in patients with focal or generalized epilepsies and when associated with other methods including antiepileptic drugs, ketogenic diet and resective surgeries approximately $60 \%$ of the patients experienced at least 50\% reduction in seizure frequency (Elliot et al, 2011).

Rutka et al. recently described the experience of the Hospital for Sick Children in Toronto, Canada, and reported good results, with $45 \%$ of cases (in a series of 41 children) a reduction of at least $50 \%$ of seizures (38\% had a reduction greater than $90 \%$ ), $12.5 \%$ had a decrease in duration and intensity of crises. Only $5 \%$ of pacemakers implanted had to be removed due to side effects (Benifla et al, 2006). Another interestingly study in a small series of patients 
with tuberous sclerosis demonstrated $82 \%$ of the cases (nine of 11 ) with at least $67 \%$ reduction in seizure frequency (Elliot et al, 2009), suggesting this could be an option for patients which epileptogenic zone could not be determined.

\subsubsection{Corpus callosotomy}

Corpus callosotomy may be a partial (anterior two thirds) or complete disconnection. Because of its inherent risks, primarily related to brain retraction, and disappointing results, this procedure has been abandoned and / or replaced by the implementation of the vagus nerve stimulator. It is particularly indicated in patients with diffuse lesion (Figure 6) or normal image that a focal focus could not be identified. Better response is observed in patients with drop attacks secondary to atonic seizures, but patients with tonic and myoclonic seizures may also have some improvement. Children submitted to corpus callosotomy are usually severely handicapped but even in these patients a disconnection syndrome may occur (Lassonde \& Sauerwein, 1997). Disconnection syndrome is a complex set of signs and symptoms that affects motor control, spatial orientation, vision, hearing and language (Jea et al, 2008) but its anatomical basis are not totally understood.

Some authors advocate the use of corpus callosotomy as an initial step for localization of surgically amenable seizure foci, in patients with apparent generalized or multifocal seizures (Lin et al, 2011).

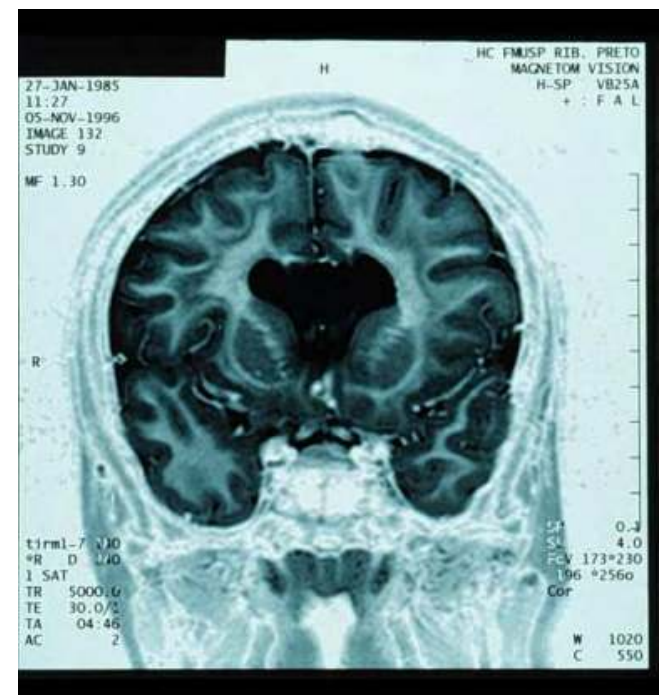

Fig. 6. Patient with a double cortex that was submitted to total callosotomy.

\subsubsection{Multiple subpial transections}

Described in 1989 by Morrell (Morrell et al, 1989), consist of the performance of multiple lines of section in cortical surface, with the goal of stopping the horizontal cortical connections and reduce the spread and propagation of epileptic activity. In order to preserve the function of the area transect vertical connections are maintained. Mainly used in surgery involving eloquent areas, provides satisfactory results in about $40 \%$ of cases. It is also indicated in cases of Landau-Kleffner syndrome. Although in these cases the result is 
controversial, improvement in communication and behavior have been reported (Gordon, 1997).

\section{Complications and prognosis}

The epilepsy surgery in childhood, at first sight, leads to higher risk of complications, since children often requires major procedures with a potential risk of installation or worsening of neurological deficits. However, long term children evolution demonstrates a significant reduction on seizure morbidity and mortality after surgery. Experienced groups report a relatively low incidence of post-operative major complications. The main acute complications are bleeding, infection and hydrocephalus. Transient neurological deficits may occur in the frontal and peri-insular resections and permanent neurological deficits is usually observed in that patients that previously eloquent areas were programmed to be involved in the resection. To deal with these surgical sequelae is essential that patients be evaluated in a well-established rehabilitation program.

With respect to prognosis, this depends greatly of the pathology and extent of surgical resection. The success rate is generally high, reaching, in our series, total control (Engel I) in $64.8 \%$ of cases (Terra-Bustamante et al, 2005), and may be even greater in certain situations, such as epilepsy and temporal tumor resection. In case of maintenance of epileptic seizures, the clinical evaluation and preoperative tests described above must be repeated and reoperation may be considered.

\section{Conclusions}

Medically intractable epilepsy is a condition with chronic recurrence of seizures that often requires surgery to reduce or eliminate them. Surgery for epilepsy in childhood has become an effective method in treating this condition, and should be indicated as early as possible. Peculiarities of epilepsy in children should be considered to achieve optimal results. Although a reduction of seizures is the primary goal of surgery, the maintenance of cognitive and motor development milestones is essential to allow the child have a quite normal life in adulthood.

Extratemporal epilepsy in children closes more cases compared to those observed in adults, but still dominates the temporal lobe as the site of ictal onset, and surgical results are very encouraging. Surgical option should take in account several factors such as child's age, underlying pathology and lesion extension. Neuronal plasticity can be an ally for the development of minor post-operative neurological deficits.

\section{References}

Abend NS, Dlugos DJ. (2008). Treatment of refractory status epilepticus: literature review and a proposed protocol. Pediatr Neurol. 38(6):377-390.

Adelson, P. D. (2001). Temporal lobectomy in children with intractable seizures. Pediatr Neurosurg 34(5): 268-277.

Alexopoulos AV, Kotagal P, Loddenkemper T, Hammel J, Bingaman WE. (2006). Long-term results with vagus nerve stimulation in children with pharmacoresistant epilepsy. Seizure. 15(7):491-503. 
Asano E, Chugani DC, Juhász C, Muzik O, Chugani HT. (2001). Surgical treatment of West syndrome. Brain Dev. 23(7):668-676.

Bailey P, Bremer F. (1938). A sensory cortical representation of the vagus nerve. J Neurophysiol; 1:4405-4412.

Benifla M, Rutka JT, Logan W, Donner EJ. (2006). Vagal nerve stimulation for refractory epilepsy in children: indications and experience at The Hospital for Sick Children. Childs Nerv Sys; 22(8):1018-1026.

Benifla M, Sala F Jr, Jane J, Otsubo H, Ochi A, Drake J, Weiss S, Donner E, Fujimoto A, Holowka S, Widjaja E, Snead OC 3rd, Smith ML, Tamber MS, Rutka JT. (2009). Neurosurgical management of intractable rolandic epilepsy in children: role of resection in eloquent cortex. J Neurosurg Pediatr; 4(3):199-216.

Bien CG, Granata T, Antozzi C, Cross JH, Dulac O, Kurthen M, Lassmann H, Mantegazza R, Villemure JG, Spreafico R, Elger CE. (2005). Pathogenesis, diagnosis and treatment of Rasmussen encephalitis: a European consensus statement. Brain; 128(Pt 3):454471.

Binder DK, Schramm J. (2006). Transsylvian functional hemispherectomy. Childs Nerv Syst.; 22(8):960-966.

Bourgeois M, Di Rocco F, Sainte-Rose C. (2006). Lesionectomy in the pediatric age. Childs Nerv Syst.; 22(8):931-935.

Cepeda C, André VM, Levine MS, Salamon N, Miyata H, Vinters HV, Mathern GW. (2006). Epileptogenesis in pediatric cortical dysplasia: the dysmature cerebral developmental hypothesis. Epilepsy Behav.; 9(2):219-235.

Chern JJ, Patel AJ, Jea A, Curry DJ, Comair YG. (2010). Surgical outcome for focal cortical dysplasia: an analysis of recent surgical series. J Neurosurg Pediatr.; 6(5):452-458.

Chugani HT. (1994). The role of PET in childhood epilepsy. J Child Neurol. Suppl 1: S82-88.

Connolly MB, Hendson G, Steinbok P. (2006). Tuberous sclerosis complex: a review of the management of epilepsy with emphasis on surgical aspects. Childs Nerv Syst; 22(8):896-908.

Coykendall DS, Gauderer MW, Blouin RR, Morales A. (2010). Vagus nerve stimulation for the management of seizures in children: an 8-year experience. J Pediatr Surg.; 45(7):1479-1483.

Cross JH, Jayakar P, Nordli D, et al. (2006). Proposed criteria for referral and evaluation of children for epilepsy surgery:recommendations of the subcommission for pediatric epilepsy surgery. Epilepsia; 47:952-959, 2006.

Dandy WE. (1928).Removal of the right cerebral hemisphere for certain tumors with hemiplegia. JAMA 90:823-825.

Delalande O, Dorfmüller G. (2008). Parasagittal vertical hemispherotomy: surgical procedure. Neurochirurgie; 54(3):353-357.

Di Rocco C, Tamburrini G. (2006). Sturge-Weber syndrome. Childs Nerv Syst; 22(8):909-921.

Diaz RJ, Sherman EM, Hader WJ. (2008). Surgical treatment of intractable epilepsy associated with focal cortical dysplasia. Neurosurg Focus.; 25(3):E6.

Dunkley C, Kung J, Scott RC, Nicolaides P, Neville B, Aylett SE, Harkness W, Cross JH. (2011). Epilepsy surgery in children under 3 years. Epilepsy Res.;93 (2-3): 96-106.

Elliott RE, Carlson C, Kalhorn SP, Moshel YA, Weiner HL, Devinsky O, Doyle WK. (2009). Refractory epilepsy in tuberous sclerosis: vagus nerve stimulation with or without subsequent resective surgery. Epilepsy Behav.; 16(3):454-460. 
Elliott RE, Morsi A, Kalhorn SP, Marcus J, Sellin J, Kang M, Silverberg A, Rivera E, Geller E, Carlson C, Devinsky O, Doyle WK. (2011). Vagus nerve stimulation in 436 consecutive patients with treatment-resistant epilepsy: long-term outcomes and predictors of response. Epilepsy Behav.; 20(1):57-63.

Gallentine WB, Mikati MA. (2009). Intraoperative electrocorticography and cortical stimulation in children. J Clin Neurophysiol.; 26(2):95-108.

García-March G, Sánchez-Ledesma MJ, Broseta J. (2008). Estimulación eléctrica vagal en el tratamiento de la epilepsia rebelde. Situación actual. Neurocirugia (Astur); 19(5):416426.

Gordon, N. (1997). The Landau-Kleffner syndrome: increased understanding. Brain Dev; 19:311-316.

Harkness WFJ. (2001). How to select the best surgical procedure for children with epilepsy. In: Epilepsy Surgery. Ed. Luders \& Comair, Philadelphia. Lippincott Williams \& Wilkins; pp 767-780.

Hart YM, Andermann F, Robitaille Y, Laxer KD, Rasmussen T, Davis R. (1998). Double pathology in Rasmussen's syndrome: a window on the etiology? Neurology; 50(3):731-735.

Hnojciková M, Nickels KC, Wetjen NM, Buchhalter JR, Raffel C, Wirrell EC. (2010). EEG and neuroimaging studies in young children having epilepsy surgery. Pediatr Neurol.; 43(5):335-340.

Horsley V. (1886). Brain Surgery. BMJ; 2: 670-675.

Iannelli A, Guzzetta F, et al. (2000). Surgical treatment of temporal tumors associated with epilepsy in children. Pediatr Neurosurg; 32(5): 248-254.

Jea A, Vachhrajani S, Widjaja E, Nilsson D, Raybaud C, Shroff M, Rutka JT. (2008). Corpus callosotomy in children and the disconnection syndromes: a review. Childs Nerv Syst.; 24(6):685-692.

Lassonde M, Sauerwein C. (1997). Neuropsychological outcome of corpus callosotomy in children and adolescents. J. Neurosurg Sci; 41:67-73.

Limbrick DD, Narayan P, Powers AK, Ojemann JG, Park TS, Bertrand M, Smyth MD. (2009). Hemispherotomy: efficacy and analysis of seizure recurrence. I Neurosurg Pediatr.;4(4):323-332.

Lin JS, Lew SM, Marcuccilli CJ, Mueller WM, Matthews AE, Koop JI, Zupanc ML. (2011). Corpus callosotomy in multistage epilepsy surgery in the pediatric population. $J$ Neurosurg Pediatr.; 7(2):189-200.

Lippé S, Bulteau C, Dorfmuller G, Audren F, Delalande O, Jambaqué I (2001). Cognitive outcome of parietooccipital resection in children with epilepsy. Epilepsia.; 51(10):2047-2057.

Machado HR, Hoffman HJ, Hwang PA. (1991). Gelastic seizures treated by resection of a hypothalamic hamartoma. Childs Nerv Syst; 7(8):462-465.

Maixner W. (2008). Hypothalamic hamartomas--clinical, neuropathological and surgical aspects. Childs Nerv Syst; 22(8):867-873.

Mastrangelo M, Mariani R, Menichella A. (2010). Eponym: Rasmussen syndrome. Eur J Pediatr.; 169(8):919-924.

McLachlan RS. Vagus nerve stimulation in epilepsy. In: Epilepsy Surgery. Ed. Luders \& Comair, Philadelphia. Lippincott Williams \& Wilkins; pp 813-819. 
Moavero R, Cerminara C, Curatolo P. (2010). Epilepsy secondary to tuberous sclerosis: lessons learned and current challenges. Childs Nerv Syst.; 26(11):1495-1504.

Mohamed A, Wyllie E, Ruggieri P, Kotagal P, Babb T, Hilbig A, Wylie C, Ying Z,Staugaitis S, Najm I, Bulacio J, Foldvary N, Lüders H, Bingaman W. (2001). Temporal lobe epilepsy due to hippocampal sclerosis in pediatric candidates for epilepsy surgery. Neurology.; 26;56(12):1643-1649.

Morrell F, Whisler WW, Bleck TP. (1989). Multiple subpial transection: a new approach to the surgical treatment of focal epilepsy. J. Neurosurg; 70, 231-239.

Obeid M, Wyllie E, Rahi AC, Mikati MA. (2009a). Approach to pediatric epilepsy surgery: State of the art, Part II: Approach to specific epilepsy syndromes and etiologies. Eur J Paediatr Neurol; 13(2):115-127.

Obeid M, Wyllie E, Rahi AC, Mikati MA. (2009b). Approach to pediatric epilepsy surgery: State of the art, Part I: General principles and presurgical workup. Eur J Paediatr Neurol; 13(2):102-114.

Park YD. (2003). The effects of vagus nerve stimulation therapy onpatients with intractable seizures and either Landau-Kleffner syndrome or autism. Epilepsy Behav; 4:286-290.

Pesaturo KA, Spooner LM, Belliveau P. (2011). Vigabatrin for infantile spasms. Pharmacotherapy.; 31(3):298-311.

Rasmussen T. (1983). Hemispherectomy for seizures revisited. Can J Neurol Sci; 10(2):71-78.

Rosenfeld WE, Roberts DW. (2009). Tonic and atonic seizures: what's next--VNS or callosotomy? Epilepsia; 50 Suppl 8:25-30.

Sakakihara Y. (2011). Treatment of West syndrome. Brain Dev.; 33(3):202-206.

Samargia SA, Kimberley TJ. (2009). Motor and cognitive outcomes in children after functional hemispherectomy. Pediatr Phys Ther.; 21(4):356-361.

Siwanuwatn R, Deshmukh P, Feiz-Erfan I, Rekate HL, Zabramski JM, Spetzler RF, Rosenfeld JV. (2008). Microsurgical anatomy of the transcallosal anterior interforniceal approach to the third ventricle. Neurosurgery; 62(6 Suppl 3):1059-1065.

Snead III OC, Martien KM. (2001). Adrenocorticotropin and steroids. In: Wyllie E, ed. The treatment of epilepsy. Principles \& Practice. Philadelphia. Lippincott Williams \& Wilkins; pp 969-975.

Téllez-Zenteno JF, Hernández Ronquillo L, Moien-Afshari F, Wiebe S. (2010). Surgical outcomes in lesional and non-lesional epilepsy: a systematic review and metaanalysis. Epilepsy Res.; 89(2-3): 310-318.

Terra-Bustamante VC, Fernandes RM, Inuzuka LM, Velasco TR, Alexandre V Jr, WichertAna L, Funayama S, Garzon E, Santos AC, Araujo D, Walz R, Assirati JA, Machado HR, Sakamoto AC. (2005). Surgically amenable epilepsies in children and adolescents: clinical, imaging, electrophysiological, and post-surgical outcome data. Childs Nerv Syst; 21(7):546-551.

Tian AG, Edwards MS, Williams NJ, Olson DM. (2011). Epilepsy surgery following brain tumor resection in children. J Neurosurg Pediatr.;7(3):229-234.

Tobias JD, Jimenez DF. (1997). Anaesthetic management during awake craniotomy in a 12year-old boy. Paediatr Anaesth.; 7(4):341-344.

Tsiptsios DI, Howard RS, Koutroumanidis MA. (2010). Electroencephalographic assessment of patients with epileptic seizures. Expert Rev Neurother.; 10(12):1869-1886.

Vendrame M, Loddenkemper T. (2010). Surgical treatment of refractory status epilepticus in children: candidate selection and outcome. Semin Pediatr Neurol.; 17(3):182-189. 
Villarejo F, Comair YG. (2000). Surgical treatment of pediatric epilepsy. In: Choux M, DiRocco C, Hockley AD, Walker M (eds.) Pediatric Neurosurgery. London, Churchill Livingstone.

Villemure JG, Daniel RT. (2006). Peri-insular hemispherotomy in paediatric epilepsy. Childs Nerv Syst.; 22(8):967-981.

Villemure JG, Mascott CR. (1995). Peri-insular hemispherotomy: surgical principles and anatomy. Neurosurgery; 37(5):975-981.

Wheless JW. (2010). Treatment of refractory convulsive status epilepticus in children: other therapies. Semin Pediatr Neurol.; 17(3):190-194.

Wier HA, Cerna A, So TY. (2011). Rufinamide for pediatric patients with lennox-gastaut syndrome: a comprehensive overview. Paediatr Drugs.; 13(2):97-106.

Yaşargil MG, Abdulrauf SI. (2008). Surgery of intraventricular tumors. Neurosurgery; 62(6 Suppl 3):1029-1040. 


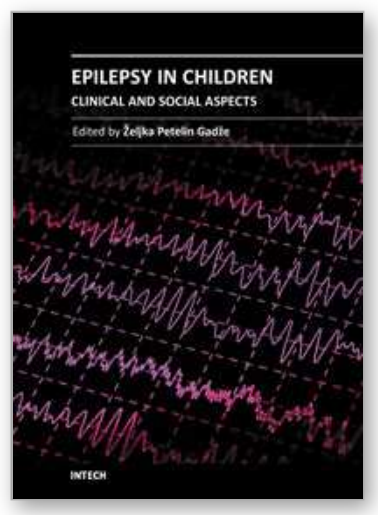

\author{
Epilepsy in Children - Clinical and Social Aspects \\ Edited by Dr. Zeljka Petelin Gadze
}

ISBN 978-953-307-681-2

Hard cover, 234 pages

Publisher InTech

Published online 15, September, 2011

Published in print edition September, 2011

Epilepsy is a neurological condition that accompanies mankind probably since its inception. About 400 years before Christ, the disease was already known by Hippocrates, who wrote the book â€œOn The Sacred Diseaseâ€. Classically, epilepsy has been defined as a chronic condition characterized by an enduring propensity to generate seizures, which are paroxysmal occurring episodes of abnormal excessive or synchronous neuronal activity in the brain. Out of all brain disorders, epilepsy is the one that offers a unique opportunity to understand normal brain functions as derived from excessive dysfunction of neuronal circuits, because the symptoms of epileptic seizures are not the result of usual loss of function that accompanies many disease that affect the brain. I am therefore extremely honoured to present this book. The 15 very interesting chapters of the book cover various fields in epileptology â $€$ " they encompass the etiology and pathogenesis of the disease, clinical presentation with special attention to the epileptic syndromes of childhood, principles of medical management, surgical approaches, as well as social aspects of the disease.

\title{
How to reference
}

In order to correctly reference this scholarly work, feel free to copy and paste the following:

Vera Cristina Terra, Américo C Sakamoto and Hélio Rubens Machado (2011). Epilepsy Surgery in Children, Epilepsy in Children - Clinical and Social Aspects, Dr. Zeljka Petelin Gadze (Ed.), ISBN: 978-953-307-681-2, InTech, Available from: http://www.intechopen.com/books/epilepsy-in-children-clinical-and-socialaspects/epilepsy-surgery-in-children

\section{INTECH}

open science | open minds

\section{InTech Europe}

University Campus STeP Ri

Slavka Krautzeka 83/A

51000 Rijeka, Croatia

Phone: +385 (51) 770447

Fax: +385 (51) 686166

www.intechopen.com

\section{InTech China}

Unit 405, Office Block, Hotel Equatorial Shanghai

No.65, Yan An Road (West), Shanghai, 200040, China

中国上海市延安西路 65 号上海国际贵都大饭店办公楼 405 单元

Phone: +86-21-62489820

Fax: $+86-21-62489821$ 
(C) 2011 The Author(s). Licensee IntechOpen. This chapter is distributed under the terms of the Creative Commons Attribution-NonCommercialShareAlike-3.0 License, which permits use, distribution and reproduction for non-commercial purposes, provided the original is properly cited and derivative works building on this content are distributed under the same license. 